Georgia State University

ScholarWorks @ Georgia State University

\title{
8-4-2019
}

\section{The Impact of the ACA on Insurance Coverage Disparities After Four Years}

Charles J. Courtemanche

Georgia State University, ccourtemanche@gsu.edu

Ishtiaque Fazlul

Georgia State University, mfazlul1@gsu.edu

James Marton

Georgia State University, marton@gsu.edu

Benjamin Ukert

Texas A\&M University

Follow this and additional works at: https://scholarworks.gsu.edu/uwrg_workingpapers

\section{Recommended Citation}

Courtemanche, Charles J.; Fazlul, Ishtiaque; Marton, James; and Ukert, Benjamin, "The Impact of the ACA on Insurance Coverage Disparities After Four Years" (2019). UWRG Working Papers. 131.

https://scholarworks.gsu.edu/uwrg_workingpapers/131

This Article is brought to you for free and open access by the Usery Workplace Research Group at ScholarWorks @ Georgia State University. It has been accepted for inclusion in UWRG Working Papers by an authorized administrator of ScholarWorks @ Georgia State University. For more information, please contact scholarworks@gsu.edu. 
W. J. Usery Workplace Research Group Paper Series

Working Paper 2019-8-4

August 2019

\section{The Impact of the ACA on Insurance Coverage Disparities After Four Years}

Charles Courtemanche University of Kentucky

Ishtiaque Fazlul Georgia State University

James Marton

Georgia State University

Benjamin D. Ukert

Texas A\&M University

Aaron Yelowitz

University of Kentucky

Daniela Zapata Author Affiliation

\section{AndRew Young SchoOl}




\title{
The Impact of the ACA on Insurance Coverage Disparities After Four Years
}

\author{
Charles Courtemanche \\ Department of Economics \\ University of Kentucky \\ Lexington, $\mathrm{KY}$ \\ courtemanche@uky.edu \\ National Bureau of Economic Research \\ Institute of Labor Economics (IZA) \\ Ishtiaque Fazlul \\ Department of Economics \\ Andrew Young School of Policy Studies \\ Georgia State University \\ Atlanta, GA \\ mfazlul1@gsu.edu \\ James Marton \\ Department of Economics \\ Andrew Young School of Policy Studies \\ Georgia State University \\ Atlanta, GA \\ marton@gsu.edu
}

Benjamin Ukert

Department of Health Policy and Management

Texas A\&M University

College Station, TX

Aaron Yelowitz*

Department of Economics

University of Kentucky

Lexington, KY

aaron@uky.edu

Daniela Zapata

Impaq International

Washington, DC

dzapata@impaqint.com

\begin{abstract}
The purpose of this chapter is to estimate the impact of the major components of the ACA (Medicaid expansion, subsidized Marketplace plans, and insurance market reforms) on disparities in insurance coverage after four years. We use data from the 2011-2017 waves of the American Community Survey (ACS), with the sample restricted to nonelderly adults. Our methods feature a difference-in-difference-in-differences model, developed in the recent ACA literature, which separately identifies the effects of the nationwide and Medicaid expansion portions of the law. The differences in this model come from time, state Medicaid expansion status, and local area pre-ACA uninsured rate. We stratify our sample separately by income, race/ethnicity, marital status, age, gender, and geography in order to examine access disparities. After four years, we find that the fully implemented ACA eliminated 44 percent of the coverage gap across income groups, with the Medicaid expansion accounting for this entire reduction. The ACA also reduced coverage disparities across racial groups by 26.7 percent, across marital status by 45 percent, and across age groups by 44 percent, with these changes being partly attributable to both the Medicaid expansion and nationwide components of the law.
\end{abstract}

Keywords: Medicaid, Affordable Care Act, Health Care Finance, Disparities in Insurance Coverage

\footnotetext{
${ }^{*}$ Corresponding Author Address: Department of Economics, 225H Gatton Business \& Economics Building, University of Kentucky, Lexington, KY, 40506-0034. Email: aaron@uky.edu.
} 


\section{INTRODUCTION}

Prior to the main implementation of the Affordable Care Act (ACA) in 2014, there were well documented disparities in insurance coverage along multiple dimensions, such as age, race, and income (Courtemanche, Marton, and Yelowitz, 2016; Yelowitz, 2016; Courtemanche et al., 2019b). The central pieces of the ACA, including the individual mandate, subsidized Marketplace coverage, and state Medicaid expansions, were designed to reduce health insurance coverage disparities by moving the U.S. closer to universal coverage (Obama, 2016; Gruber and Sommers, 2019). The purpose of this paper is to examine the extent to which the ACA reduced disparities in coverage after four years (2014-2017).

While gains in insurance coverage after the ACA have been well documented, relatively few papers in this literature examine how the ACA affected coverage disparities and none use data from 2017. Courtemanche et al. (2017) estimate the first-year impact of the ACA on coverage using difference-in-difference-in-differences (DDD) models where the differences come from time, state Medicaid expansion decisions, and pre-ACA local area uninsured rate. Similar to the approach taken by Finkelstein (2007) and Miller (2012) to study other coverage expansions, this strategy leverages the propensity for universal coverage initiatives to provide the most intense "treatment" in local areas with the highest pre-reform uninsured rates. Using data from the American Community Survey (ACS), Courtemanche et al. (2017) find that the ACA increased coverage by an average of 5.9 percentage points in Medicaid expansion states compared to 2.8 percentage points in non-expansion states in 2014. In subsample analyses, the authors show that the fully implemented ACA (including the Medicaid expansion) reduced but did not eliminate the coverage disparities based on education, race, age, and marital status after one year. 
Courtemanche et al. (2018a) use the same research strategy and data from the Behavioral Risk Factor Surveillance System (BRFSS), finding that the ACA reduced but did not eliminate the coverage disparity between those with incomes above versus below the median after two years (2014-2015). Frean et al. (2017) also use data through 2015 and a DDD approach to find that coverage gains from the Medicaid expansion and Marketplace premium subsidies are larger among childless adult couples than among single adults or adults with children, but the increase from the individual mandate is largest among singles. Courtemanche et al. (2019b) use three years of post-ACA data (2014-2016) from the ACS and finds that the ACA Medicaid expansion eliminated 43 percent of the coverage gap across income groups. In addition, the authors find that the ACA reduced but did not eliminate coverage disparities across racial groups, age groups, and marital status. These reductions were partly attributable to both the Medicaid expansion and nationwide components of the law.

Other studies in the literature focus solely on the ACA's Medicaid expansion, using difference-in-differences (DD) models to compare changes in coverage over time between Medicaid expansion and non-expansion states. Wehby and Lyu (2018) include two years of postACA data (2014-2015) from the ACS and show that the Medicaid expansion reduced but did not eliminate the coverage disparity across age and racial groups. Conversely, Yue et al. (2019) find that the ACA Medicaid expansion led to smaller gains among low-income Hispanics than other low-income individuals, implying a widened disparity. Kaestner et al. (2017) and Wherry and Miller (2016) provide evidence that the ACA Medicaid expansion increased insurance coverage among those with low incomes or levels of education, implying reduced socioeconomic disparities in coverage. Benitez et al. (2018) focuses on Kentucky, finding that much of the 
reduction in the uninsured rate is due to large coverage gains from areas with higher concentrations of poverty.

We contribute to this literature by using the DDD method described above and elsewhere (Courtemanche et al., 2018b) to uncover the causal impact of the 2014 ACA provisions, both with and without the Medicaid expansion, on coverage disparities after four years. To the best of our knowledge we are the first to include data from 2017 in such an analysis. Given the uncertainty surrounding the future of the ACA, new evidence regarding the impact of the ACA provided by each new year of survey data is extremely valuable to researchers and policy makers. As in Courtemanche et al. (2019b), we evaluate changes in coverage disparities by stratifying our sample by income, race/ethnicity, marital status, age, gender, and geography. We use data from the American Community Survey (ACS) between 2011 and 2017. The ACS is commonly used in the literature because it includes multiple categories of insurance coverage, allowing us to evaluate how the ACA affected coverage disparities via changes to both private (Marketplace) and public (Medicaid) coverage. The ACS includes approximately 3,000,000 observations per year and relatively narrow geographic identifiers, allowing us to precisely estimate the effects for states and many local areas. A final benefit is that the mandatory nature of the ACS reduces concerns about sample selection amongst respondents.

After four years, our results suggest that the fully implemented ACA eliminated 44 percent of the coverage gap across income groups, with the Medicaid expansion accounting for this entire reduction. The ACA also reduced coverage disparities across racial groups by 26.7 percent, across marital status by 45 percent, and across age groups by 44 percent, with these changes being partly attributable to both the Medicaid expansion and nationwide components of the law. 


\section{DATA}

We use data from the American Community Survey’s (ACS) 2011 through 2017 survey waves. The ACS is a nationwide mandatory random survey across all 50 states and the District of Columbia that samples about one percent of the U.S. population annually. Each year of the survey results in about 3,000,000 individual responses per year. ${ }^{1}$ The mandatory feature of the survey reduces concerns about sample selection amongst respondents. For this study, we restrict the ACS sample to respondents aged 19 to 64 because the ACA was not intended to affect the health coverage of children or those older than 64 . We limit the first sample year to 2011 to only isolate the effects of the 2014 provisions of the ACA, and thereby avoid capturing the effect of earlier changes in the insurance market, such as the 2010 dependent coverage mandate that allowed dependents to remain on their parent's insurance plan until their $26^{\text {th }}$ birthday.

The ACS includes geographic identifiers for each survey respondent. In addition to state identifiers, the ACS identifies smaller geographic areas called Public Use Microdata Areas (PUMAs), which represent approximately 2,300 areas of at least 100,000 people nested entirely within a state. ${ }^{2}$ The granularity of the PUMA identifier is important for our study since a PUMA can better represent local characteristics than a state identifier.

To detect a causal impact of the ACA marketplace component of the ACA, we utilize local within-state variation in uninsured rates in 2013. Ideally, we would use the within state PUMA identifier to measure uninsured rates, however, the PUMA definitions changed, new boundaries were introduced in the 2010 Census, and the new boundaries were applied to the 2013 ACS wave and later. This complicates our analysis as we cannot identify the same

\footnotetext{
${ }^{1}$ The survey can be completed online or by mailing in a paper questionnaire. In-person interviews are done with respondents in group quarters. See https://www.census.gov/content/dam/Census/programssurveys/acs/about/ACS Information_Guide.pdf

${ }^{2}$ For more information, see: https://www.census.gov/geo/reference/puma.html
} 
geographic region across time before and after the 2014 ACA components. We address this problem by following Courtemanche et al. (2017) and identifying core-based statistical areas (CBSAs) using the old and new PUMA classification systems. Some CBSAs span multiple states and we isolate the portion of the CBSA in each state as separate local areas. In other cases, CBSAs do not cover all areas within a state, and we create additional local areas for the nonCBSA portion in each state. These adjustments avoid dropping respondents from the sample living in multistate CBSAs or areas that are not part of a CBSA. Our dataset consists of 630 local CBSA and non-CBSA areas that each contain between 356 and 78,781 ACS respondents in 2013, with a median of 1,020 and a mean of 2,811 respondents. This implies that our pre-ACA uninsured rates are computed from a reasonably large sample in each local area.

The ACS collects a large number of socio-demographic characteristics relevant to execute our study and it includes a question on health insurance coverage that allows us to evaluate how the ACA affected both private and public coverage. The ACS asks each individual "Is this person CURRENTLY covered by any of the following types of health insurance or health coverage plans?" and respondents select from eight types of health insurance categories; "insurance though a current or former employer or union", "insurance purchased directly from an insurance company", "Medicare", "Medicaid, Medical Assistance, or any kind of governmentassistance plan for those with low incomes or a disability", "TRICARE or other military health care", "VA (including those who have ever used or enrolled for VA health care)", "Indian Health Service", and "any other type of health insurance or health coverage plan." ${ }^{3}$ Respondents can choose more than one type of insurance coverage and we classify only those answering "no" to all eight categories as uninsured. We create six binary outcome variables based on the ACS

\footnotetext{
${ }^{3}$ See, for example, http://www2.census.gov/programs-surveys/acs/methodology/questionnaires/2014/quest14.pdf
} 
insurance coverage question: any insurance, any private insurance (either employer sponsored or directly purchased), employer-sponsored insurance, directly purchased insurance, Medicaid, and any other coverage (defined as coverage as neither private nor Medicaid coverage). These categories are not mutually exclusive due to the possibility of multiple sources of coverage.

Additionally, the ACS collects information on age, gender, race/ethnicity, origin, family structure, education, labor force participation, and household income. We use this information to create a large number of control variables. Specifically, we create dummy variables for the age of the respondent (binary indicators for each year from 19 to 64), female, race/ethnicity (nonHispanic white, non-Hispanic black, Hispanic, and other race/ethnicity), foreign born, and U.S. citizenship status. We generate from the family structure responses a binary variable indicating whether the individual is married and separate indicators counting the number of children under the age of 18 living in the household (one, two, three, four, and five or more). We create separate binary indicators for the highest level of completed education (less than a high school degree, high school degree, some college, and college graduate), and we measure labor force outcomes with binary variable indicating whether the individual is a student or not, whether the individual is unemployed or not, and with the continuous Bureau of Labor Statistics' annual state unemployment rate. Lastly, we measure household income by first transforming the income information into percentages relative to the Federal Poverty Limit (FPL), and then create 50 dummies measuring the separate impact for each 10-point increment of income as a percentage of the FPL (with the highest category including everyone over 500 percent).

We add to the ACS state-level ACA variables from the Kaiser Family Foundation. Specifically, we include binary variables on whether a state implemented a Medicaid expansion via the ACA. The majority of states expanded Medicaid effective January 1, 2014, but several 
states expanded at a later time. At the end of 2017, 32 states expanded their Medicaid program and 25 states expanded Medicaid as of January 1, 2014. Seven states expanded at a later time Michigan (expansion effective date 4/1/2014), New Hampshire (8/15/2014), Pennsylvania (1/1/2015), Indiana (2/1/2015), Alaska (9/1/2015), Montana (1/1/2016), and Louisiana $(7 / 1 / 2016)$.

Finally, we also collect information from the Kaiser Family Foundation regarding the functionality of the 2014 ACA insurance marketplaces. We include dummy variables indicating whether a state set up their own private insurance exchange (as opposed to using the federal exchange) and whether the exchange experienced glitches. These variables speak to aspects that may be related to frictions of outreach and sign-up of the uninsured to Marketplace insurance plans, as well as concerns that these decisions may be correlated with the decision to expand Medicaid coverage.

Table 1 provides pretreatment means and standard deviations for the insurance coverage outcomes of interest, while table A1 does the same for the controls. We also stratify the sample into four groups based on whether the respondent's state expanded Medicaid and whether her local area's pretreatment uninsured rate was above or below the sample median. Table 1 shows that in the baseline year of 201379 percent of the sample was enrolled in some type of coverage, including 11 percent with Medicaid and 60 percent with employer-provided coverage. For both the high-uninsured (columns 2 and 4) and low-uninsured (columns 3 and 5) rate subgroups, individuals in Medicaid expansion states were slightly more likely to be covered in 2013 than those in non-expansion states, with the differences being driven entirely by Medicaid coverage. Our DDD model described in the next section will account for such baseline differences. Figure 1 presents changes in our coverage measures between 2011 and 2017, stratified into the same 
four groups. With six coverage outcomes and four groups, there are a total of 24 lines given in figure 1. In general, the pre-ACA trends in the figure do not appear to differ meaningfully by state Medicaid expansion status or local area pre-ACA uninsured rate category. This provides preliminary justification for our use of the pre-ACA uninsured rate and Medicaid expansion variables as sources of identification in our analysis. Figure 1 shows that the probabilities of having any coverage, privately purchased coverage, any private coverage, and Medicaid increased in 2014 and generally continued to grow over time. One exception is the dip in individually purchased coverage observed in 2017.

\section{METHODS}

Our empirical methodology follows several prior studies that aimed to separately identify the impacts of both the Medicaid and private components of the ACA (Courtemanche et al., 2017; 2018a; 2018b; 2019a; 2019b; 2019c). Specifically, we estimate DDD models where the three "differences" are before versus after the ACA's implementation, whether or not the state participated in the ACA's Medicaid expansion, and the "dose" of the treatment, as measured by the local area's pre-ACA uninsured rate. The model, estimated for both the full sample and various subsamples, takes the following form:

$$
\begin{gathered}
I_{\text {iast }}=\beta_{0}+\beta_{1}\left(\text { UNINSURED }_{a s} * \text { POST }_{t}\right)+\beta_{2}\left(\text { MEDICAID }_{s} * \text { POST }_{t}\right)+ \\
\beta_{3}\left(\text { UNINSURED }_{a s} * \text { MEDICAID }_{s} * \text { POST }_{t}\right)+\beta_{4} \boldsymbol{X}_{\text {iast }}+\tau_{t}+\alpha_{a s}+\varepsilon_{\text {iast }}
\end{gathered}
$$

$I_{\text {iast }}$ is a binary variable for whether individual $i$ living in local area $a$ within state $s$ has insurance coverage in year t. UNINSURED $D_{a s}$ is the 2013 baseline (pre-treatment) uninsured rate in local 
area $a$ in state $s, M E D I C A I D_{s}$ and $P_{t} O S T_{t}$ are indicators for whether state $s$ participated in the ACA's Medicaid expansion and whether or not year $t$ is after the ACA's implementation (2014 or later), respectively. ${ }^{4} \boldsymbol{X}_{\text {iast }}$ is a vector of the aforementioned control variables, while $\tau_{t}$ and $\alpha_{a s}$ are year and local area fixed effects and $\varepsilon_{\text {iast }}$ is the error term. Note that we do not separately include $P_{\text {OST }}, U N I N S U R E D_{a s}, M E D I C A I D_{s}$, or MEDICAID $* U N I N S U R E D_{a s}$ since these terms are subsumed by the time and local area fixed effects.

Following the prior studies listed above, we consider $\gamma_{1} * U N I N S U R E D_{a s}$ to represent the impact of the ACA in areas without the Medicaid expansion - in other words, the impact of its private portion. This implicitly assumes that an area with a 0 percent uninsured rate is untreated by the ACA, meaning that $\gamma_{2}$ is considered to capture unobserved state-by-time confounders. Accordingly, the effect of the Medicaid expansion is also assumed to be proportional to the baseline uninsured rate in expansion states: $\gamma_{3} * U N I N S U R E D_{a s} *$ MEDICAID $D_{\text {st }}$. The full effect of the ACA in Medicaid expansion states is therefore $\gamma_{1} * U N I N S U R E D_{a s}+\gamma_{3} * U N I N S U R E D_{a s}$. The predicted effect of the ACA at the sample mean baseline uninsured rate is $\gamma_{1} * \overline{U N I N S U R E D_{a s}}$ in states that refused the Medicaid expansion and $\gamma_{1} * \overline{U N I N S U R E D_{a s}}+\gamma_{3} * \overline{U N I N S U R E D_{a s}}$ in Medicaid expansion states. The baseline uninsured rate for each subsample is re-computed using only respondents in that particular subsample.

\section{RESULTS}

\footnotetext{
${ }^{4}$ For states that expanded Medicaid later than 2014, we adjust the timing of the "post" period in the $M E D I C A I D_{s} *$ POST $_{t}$ and UNINSURED $D_{a s} * M E D I C A I D_{s} *$ POST $_{t}$ interactions accordingly.
} 
Table 2 reports the implied effects of the ACA at the average pre-ACA uninsured rate for the full non-elderly adult sample based on coefficient estimates from the DDD regression described by equation (1). The first column shows results for any coverage, while the next five columns show the effects on different sources of coverage. The first row reports the pre-ACA uninsured rate. Indicators of statistical significance are given at the 0.1 percent, 1 percent, and 5 percent level. For each regression we separately report: a) the implied effects of the Medicaid expansion alone and b) the fully implemented ACA, which includes the Medicaid expansion as well as the other main components of the ACA, such as subsidized Marketplace coverage. This approach allows for easier comparison to previous work that focused on the Medicaid expansion alone.

The first column of table 2 suggests that at the average pre-ACA uninsured rate of 20.3 percent, the Medicaid expansion increased the proportion of residents with insurance coverage by 5.1 percentage points over the four-year period of 2014-2017. In comparison, the fully implemented ACA led to an 8.7 percentage point increase in coverage, implying that the package of nationwide reforms contributed the remaining 3.6 percentage points. The remaining columns examine sources of coverage, where we consider any source of private coverage, any employersponsored (ESI) plan, any individually purchased plan, Medicaid, and any other coverage source. Our results suggest that, in an area with the mean pre-ACA uninsured rate, the fully implemented ACA increases private coverage by 2.8 percentage points. This is driven by increases in both ESI (1.8 percentage points) and individually purchased coverage (1 percentage point). The full ACA increased Medicaid coverage by 6.2 percentage points, most of which comes from the Medicaid expansion component of the law (5.9 percentage points). For the full sample, the Medicaid expansion alone statistically significantly affects the probability of having Medicaid only. The 
full ACA with the Medicaid expansion, on the other hand, has a statistically significant positive effect on having any private insurance, ESI, as well as individually purchased insurance.

The validity of the identifying assumptions of our baseline DDD model cannot be directly tested. We test the validity of these assumptions indirectly by reporting the pre-ACA coefficients from an event study model where the treatment variables are interacted with the full set of year fixed effects. We report the results from this event study analysis separately in tables 3 and 4 . Table 3 reports only the estimated pre-treatment (2011 and 2012) coefficients from the event study, while table 4 reports only the post-treatment implied effects (separately for the years 2014, 2015, 2016, and 2017). This split allows us to focus on the indirect test of our identifying assumptions in table 3 and decomposing the year-by-year effects of the ACA in the post-period in table 4. With that in mind, we start by examining the results from table 3 . Unlike in table 2, the numbers in table 3 are not implied effects but estimated coefficients taken directly from the event study regressions. Here we would expect around 5 percent of the pre-treatment coefficients to be significant by chance. A substantially higher percentage of significant results in the preperiod will call our identification strategy into question. We see that 2 out of 24 coefficients ( 8.3 percent) are significant in table 3 , which gives us confidence in a casual interpretation of our results.

Table 4 reports the implied effect of the ACA at mean pre-reform uninsured rate of 20.3 percent in an event study specification where the treatment variables are interacted with the full set of year fixed effects. As mentioned above, this table reports only the post-treatment implied effects (for the years 2014, 2015, 2016, and 2017) from the same event study model that generates the results reported in table 3 . The table includes indicators at the .1 percent, 1 percent, and 5 percent significance level to show if the estimates are statistically significantly different 
between the first and last post-years (i.e. 2014 vs. 2017) and between 2016 vs. 2017 as well. Three sets of implied effects are reported in table 4: the impact of the ACA without the Medicaid expansion in panel I, the impact of the Medicaid expansion alone in panel II, and the impact of the full ACA with the Medicaid expansion (which is the sum of the first two effects) in panel III. This table essentially shows how the effect of the ACA changed over time.

The first column in panel I shows that the effect of the ACA without the Medicaid expansion on having any insurance increased year over year in the post-reform period until 2016 and then decreased in 2017. The first column in panel II shows that the Medicaid expansion alone led to an increased probability of having any insurance year over year in all four postreform years. The combination of these two facts leads to an increased probability of having any insurance as a result of the fully implemented ACA year over year until 2016 and a plateau in the probability of having any insurance between 2016 and 2017 (see the first column in panel III). To give a sense of the magnitude of these changes, the probability of having any insurance due the to the fully implemented ACA increased from 6.1 percentage points in 2014 to 10.7 percentage points in 2016. Instead of growing further in 2017, we see an increase in the probability of having any insurance due to the fully implemented ACA of only 10.6 percentage points in 2017 , which is not statistically significantly different than the 2016 estimate.

Looking at the sources of insurance in panel $\mathrm{I}$, we see an increase in any private coverage year over year due to the ACA without the Medicaid expansion until 2016 (2.8, 4.5 and 4.7 percentage points for 2014, 2015 and 2016 respectively compared to pre-ACA coverage) and a decrease in coverage growth in 2017 (only a 3.5 percentage point increase in 2017). This change in any private coverage appears to be driving the overall change in coverage due to the ACA without the Medicaid expansion (which increases by 2.9, 4.6, 4.8, and 3.6 percentage points for 
2014, 2015, 2016, and 2017 respectively compared to pre-ACA coverage). Turning to the sources of insurance in panel II, Medicaid coverage increases year over year in the post-reform period due to the Medicaid expansion from 3.3 percentage points in 2014 to 8 percentage points in 2017. As expected, this change in Medicaid coverage appears to be driving the overall change in coverage due to the Medicaid expansion (which increases by 3.2, 4.7, 5.9 and 7 percentage points in 2014, 2015, 2016 and 2017 respectively compared to pre-ACA coverage).

As mentioned above, panel III in table 4 shows that between 2016 and 2017 there was a plateau in the growth in "any insurance" due to full implementation of the ACA (an increase of 10.7 percentage points in 2016 and 10.6 percentage points in 2017 as compared to the pre-ACA period). From the sources of insurance columns, we see that this was the result of continued increasing growth in Medicaid coverage over each of the post-period years (3.5, 6.6, 7.9 and 8.4 percentage point increase in coverage in $2014,2015,2016$, and 2017) and growth in private insurance coverage in 2014 and 2015, followed by a plateau and a reduction in the growth of coverage from 2015 to 2017 (2.8, 3.2, 3.2 and 2.6 percentage point increase in coverage in 2014, 2015, 2016, and 2017).

Tables 5, 6, and 7 report the implied effects of the Medicaid expansion and the fully implemented ACA for various subsamples of interest at the mean pre-ACA uninsured rates for each of those subsamples. Like table 2, these tables report the implied effects of Medicaid expansion alone and full ACA following the DDD design in equation 1. The first rows for each subsample show the pre-ACA uninsured rate for that subsample, which we use to calculate the pre-ACA disparities in coverage. The two panels of table 5 stratify the sample into subsamples by income and race. Since each subsample must contain enough 2013 respondents to accurately compute local area uninsured rates, we are limited to a maximum of two or three subsamples per 
stratification, as in Courtemanche et al. (2019b). For income, we consider three categories: those with income under 138 percent of the FPL, those between 138 and 400 percent, and those above 400 percent. The under 138 percent of the FPL group was made eligible for Medicaid in states that expanded their Medicaid programs via the ACA. Additionally, those between 100 and 138 percent of the FPL were eligible for subsidized Marketplace coverage in non-expansion states. Those between 138 and 400 percent of the FPL were made eligible for subsidized Marketplace coverage in all states. The highest income group (above 400 percent of the FPL) was also able to purchase non-subsidized Marketplace coverage in all states. The uninsured rate for those in the highest income group in 2013 was 6.7 percent, while it was 39.5 percent for the lowest income group. This implies a 32.8 percentage point coverage gap between the low and high income group.

According to the first column of table 5, panel I, this 32.8 percentage point coverage gap was reduced by 17.4 percentage points $(=18.4$ percentage point reduction for the lowest income group - 1 percentage point reduction for the highest income group) due to the Medicaid expansion. This represents a 53 percent reduction in the coverage gap between the low and high income groups. The fully implemented ACA, which includes the Medicaid expansion, but also influences the coverage of higher income individuals through the national components of the ACA, reduced the low-income coverage gap by 44 percent. Turning to sources of coverage, several results emerge. First, the coverage gains among the low income occurred completely through Medicaid coverage in expansion states. Moreover, some of the coverage expansion among middle income individuals occurred via Medicaid coverage even though this income range was not eligible for coverage via the Medicaid expansion. Courtemanche, Marton, and Yelowitz (2019) further document this phenomenon. 
We next examine the race stratification in panel II of table 5. The racial coverage gap in 2013 was 16.1 percentage points, with non-whites having an uninsured rate of 30.6 percent, while non-Hispanic whites had an uninsured rate of 14.5 percent. Our results suggest that the Medicaid expansion reduced the 16.1 percentage point coverage gap by 2.4 percentage points (15 percent), while the fully implemented ACA reduced the gap by 4.3 percentage points (26.7 percent). The results for sources of coverage show that the non-whites enjoy larger gains acrossthe-board, i.e., the effects of the full ACA on all types of coverage are larger for non-whites compared to whites.

Panel I of table 6 examines disparities of coverage by marital status. In 2013 unmarried individuals had a 27.2 percent uninsured rate, while married individuals had a 14.1 percent uninsured rate giving rise to a 13.1 percentage point coverage gap between the two groups. This unmarried coverage gap was reduced by 5.3 percentage points ( 40.5 percent) by the Medicaid expansion, while the fully implemented ACA reduced this coverage gap by 5.9 percentage points (45 percent). The shrinking gap is attributable to larger gains in ESI and Medicaid coverage among the unmarried.

Panel II of table 6 splits the sample into four age groups: 19-26 years of age, 27-34 years of age, 35-49 years of age, and 50-64 years of age. The rationale for separating 19-26 year olds from 27-34 year olds is that the former was previously affected by the 2010 dependent coverage mandate. Because of the mandate, it is possible that the effect of the 2014 ACA provisions could be weaker among 19-26 than 27-34 year olds. The data, however, shows that those aged 19-26 years still had the highest uninsured rate (27 percent) among the age groups in 2013 , three years after the dependent coverage mandate took effect. Those aged 50-64 had the lowest uninsured rate of 14.5 percent. This implies a young adult coverage gap of 12.5 percentage points. The 
Medicaid expansion reduced this coverage gap by 4.6 percentage points ( 36.8 percent) and the fully implemented ACA reduced it by 5.5 percentage points ( 44 percent). The larger gain among 19-26 year olds is driven by a much larger increase in Medicaid coverage ( 9.7 percentage points compared to 4.3 percentage points among 50-64 year olds due to the full ACA).

Panel I of table 7 stratifies the sample by gender. Prior to the ACA, we observe a relatively small coverage gap of 3.7 percentage point for men (22.3 percent uninsured rate for males vs. 18.6 percent for females). Our results suggest that the Medicaid expansion actually increased the size of this coverage gap by 24.3 percent since it reduced the uninsured rate for women by a greater degree than it did for men. Conversely, the fully implemented ACA reduced the size of the gender coverage gap by 5.4 percent due to a larger effect of full ACA on private coverage for men as compared to women.

Panel II of table 7 stratifies the sample by urban vs. rural location. When it comes to health care access, rural individuals are generally considered a vulnerable population. The uninsured rate in 2013 was 21.1 percent for rural non-elderly adults as compared to 20.3 percent for urban non-elderly adults. So the initial disparity in terms of insurance coverage was 0.8 percentage points. The fully implemented ACA reduced this disparity by 2.1 percentage points whereas the Medicaid expansion alone led to a 2.7 percentage point reduction in the rural coverage gap. An increase in ESI coverage for urban individuals led to a lower net effect of the fully implemented ACA on the rural coverage gap as compared to the Medicaid expansion alone.

\section{DISCUSSION}

Prior to the main implementation of the Affordable Care Act (ACA) in 2014, there were well- documented disparities in insurance coverage along multiple dimensions, such as age, race, 
and income (Courtemanche, Marton, and Yelowitz, 2016; Yelowitz, 2016; Courtemanche et al., 2019b). In this paper, we investigate whether newly available calendar year 2017 data from the ACS helps to provide further insights into the ACA's effects on insurance disparities.

There are three main overall findings of our investigation. First, there were further reductions in coverage disparities in 2017. After four years, the fully implemented ACA reduced coverage disparities across income groups by 44 percent, racial groups by 27 percent, and across age groups by 44 percent. These results are larger than the ones estimated by Courtemanche et al., (2019b) using only three years of post-implementation data. We also confirm their finding that the ACA reversed the small rural coverage gap that existed prior to the implementation of the ACA. In addition, reductions in the size of the gender coverage gap emerged that were not present when using only three years of post-implementation data. This reduction is due to the larger effect of the private components of the ACA expansion on insurance coverage for men than women. Finally, the reductions in coverage disparities across marital status were slightly smaller with four years of post-implementation data than the ones obtained with only three years (44 percent versus 45 percent, respectively).

Second, the gains in insurance coverage growth slowed down in 2017 due to a reduction in the growth of private insurance coverage, most of which is due to a reduction in ESI coverage, but also due to a reduction in the growth of individually purchased coverage. Even though we don't have enough data to understand the mechanisms driving this change, it is possible that the 2016 presidential election had a chilling effect on private insurance. In January 2017, President Trump signed his first executive order directing federal agencies to exercise all authority and discretion available to them to waive, defer, grant exemptions from, or delay the implementation 
of any provision or requirement of the ACA. Whether this and other actions taken by President Trump had an effect on private insurance coverage is a topic that needs further investigation.

Third, our results show that the reductions in coverage disparities are due to both the Medicaid expansion and to the private components of the ACA. Reductions in the growth of private insurance coverage could dampen the reductions in coverage disparities. For example, the reduction in coverage disparities across income groups was larger using four years of data compared to using three years of data, but only slightly (44 percent versus 43 percent, respectively). Similarly, the slight reduction in the coverage disparity by marital status in 2017 is due to a smaller increase in private insurance coverage - particularly individually purchased insurance - among unmarried individuals.

One limitation of our work is that our disparity analyses assume that the subsamples are exogenously determined. Income is one source of stratification that might seem particularly likely to adjust endogenously in response to the 2014 ACA provisions. Kaestner et al. (2017) and Leung and Mas (2018) found little impact of the ACA Medicaid expansions on work effort, implying that the effect on income should be minimal. Gooptu et al. (2016) found no impact of the ACA in part-time versus full-time employment or job reductions in 2014. Duggan et al. (2017), on the other hand, found that while labor market outcomes in the aggregate were not significantly affected by the ACA, labor force participation reductions in areas with higher potential exchange enrollment were offset by increases in labor force participation in areas with higher potential Medicaid enrollment.

Our results are broadly consistent with those reported in the Medicaid expansion literature in that both the Medicaid expansion and the fully implemented ACA generally reduce but do not eliminate coverage disparities. These results imply that full repeal of the ACA would 
exacerbate these disparities. Additionally, it is possible that changes to the ACA after 2017, including regulatory changes, such as Medicaid work requirements, and the elimination of the individual mandate, would lead to further changes in disparities. For example, our finding that the Medicaid expansion eliminated 53 percent of the coverage gap across income groups may change if Medicaid work requirements are widely implemented and end up reducing enrollment. Thus, more work is needed to examine the impact of the ACA as economic conditions change and the ACA itself changes.

\section{REFERENCES}

Benitez Joseph A., E. Kathleen Adams, and Eric E. Seiber. 2018. "Did Health Care Reform Help Kentucky Address Disparities in Coverage and Access to Care Among the Poor?," Health Services Research 53(3):1387-1406.

Courtemanche, Charles, James Marton, and Aaron Yelowitz. 2016. "Who Gained Insurance Coverage in 2014, the First Year of Full ACA Implementation?," Health Economics 25(6):778-84.

Courtemanche, Charles, James Marton, and Aaron Yelowitz. 2019. "Medicaid Coverage Across the Income Distribution under the Affordable Care Act." In Medicaid: Enrollment, Eligibility, and Key Issues, edited by Daniel Lanford. New York: Nova Science.

Courtemanche, Charles, James Marton, Benjamin Ukert, Aaron Yelowitz, and Daniela Zapata. 2017. "Impacts of the Affordable Care Act on Health Insurance Coverage in Medicaid Expansion and Non-Expansion States," Journal of Policy Analysis and Management 36(1):178-210. 
Courtemanche, Charles, James Marton, Benjamin Ukert, Aaron Yelowitz, and Daniela Zapata. 2018a. "Early Effects of the Affordable Care Act on Health Care Access, Risky Health Behaviors, and Self-Assessed Health,” Southern Economic Journal 84(3):660-691.

Courtemanche, Charles, James Marton, Benjamin Ukert, Aaron Yelowitz, and Daniela Zapata. 2018b. "Effects of the Affordable Care Act on Health Care Access and Self-Assessed Health after 3 Years," Inquiry: The Journal of Health Care Organization, Provision and Financing 55:1-10.

Courtemanche, Charles, James Marton, Benjamin Ukert, Aaron Yelowitz, and Daniela Zapata. 2019a. "Effects of the Affordable Care Act on Health Behaviors after 3 Years," Eastern Economic Journal 45(1):7-33.

Courtemanche, Charles, James Marton, Benjamin Ukert, Aaron Yelowitz, Daniela Zapata, and Ishtiaque Fazlul. 2019b. "The Three-Year Impact of the Affordable Care Act on Disparities in Insurance Coverage," Health Services Research, 54(S1):307-316.

Courtemanche, Charles, Andrew Friedson, Andrew P. Koller, and Daniel I. Rees. 2019c. "The Affordable Care Act and Ambulance Response Times," Journal of Health Economics, 67.

Duggan, Mark, Gopi S. Goda, and Emilie Jackson. 2017. The Effects of the Affordable Car Act on Health Insurance Coverage and Labor Market Outcomes. National Bureau of Economic Research Working Paper 23607.

Finkelstein, Amy. 2007. "The Aggregate Effects of Health Insurance: Evidence from the Introduction of Medicare," Quarterly Journal of Economics 122:1-37. 
Frean, Molly, Jonathan Gruber, and Benjamin D. Sommers. 2017. "Premium Subsidies, the Mandate, and Medicaid Expansion: Coverage Effects of the Affordable Care Act," Journal of Health Economics 53:72-86.

Gooptu, Angshuman, Asako S. Moriya, Kosali I. Simon, and Benjamin D. Sommers. 2016. "Medicaid Expansion did not Result in Significant Employment changes or Job Reductions in 2014," Health Affairs 35(1):111-118.

Gruber, Jonathan and Benjamin D. Sommers. 2019. "The Affordable Care Act's Effects on Patients, Providers and the Economy: What We've Learned so Far.” National Bureau of Economic Research Working Paper 25932, National Bureau of Economic Research, June. http://www.nber.org/papers/w25932.

Kaestner, Robert, Bowen Garrett, Jiajia Chen, Anuj Gangopadhyaya, and Caitlyn Fleming. 2017. "Effects of the ACA Medicaid Expansion on Health Insurance Coverage and Labor Supply," Journal of Policy Analysis and Management 36(3):608-642.

Leung, Pauline and Alexandre Mas. 2018. "Employment Effects of the Affordable Care Act Medicaid Expansions,”. Industrial Relations 57(2):206- 234.

Miller, Sarah. 2012. “The Effect of Insurance on Emergency Room Visits: An Analysis of the 2006 Massachusetts Health Reform,” Journal of Public Economics 96:893-908.

Obama, Barack. 2016. "United States Health Reform: Progress to Date and Next Steps,” Journal of the American Medical Association 316(5):525-532.

Wehby, George L. and Wei Lyu. 2018. "The Impact of the ACA Medicaid Expansions on Health Insurance Coverage through 2015 and Coverage Disparities by Age, Race/Ethnicity, and Gender," Health Services Research 53(2):1248-1271. 
Wherry, Laura R. and Sarah Miller. 2016. "Early Coverage, Access, Utilization, and Health Effects Associated with the Affordable Care Act Medicaid Expansions: A QuasiExperimental Study,” Annals of Internal Medicine 164(12):795-803.

Yelowitz, Aaron. 2016. "How Did the ACA Affect Health Insurance Coverage in Kentucky?" Schnatter Institute Working Paper. John H. Schnatter Institute for the Study of Free Enterprise, University of Kentucky, Accessed September. http://isfe.uky.edu/sites/ISFE/files/research-pdfs/Schnatter.2017.Yelowitz.pdf

Yue, Dahai, Petra W. Rasmussen, and Ninez A. Ponce. 2018. "Racial/Ethnic Differential Effects of Medicaid Expansion on Health Care Access," Health Services Research 53(5):36403656. 


\begin{tabular}{lccccc}
\hline & Full sample & $\begin{array}{c}\text { Medicaid } \\
\text { expansion; } \\
\text { at or above } \\
\text { median } \\
\text { baseline } \\
\text { uninsured }\end{array}$ & $\begin{array}{c}\text { Medicaid } \\
\text { expansion; } \\
\text { below } \\
\text { median } \\
\text { baseline } \\
\text { uninsured }\end{array}$ & $\begin{array}{c}\text { Non- } \\
\text { expansion; at } \\
\text { or above } \\
\text { median } \\
\text { baseline } \\
\text { uninsured }\end{array}$ & $\begin{array}{c}\text { Non- } \\
\text { expansion; } \\
\text { below } \\
\text { median } \\
\text { baseline } \\
\text { uninsured }\end{array}$ \\
\hline $\begin{array}{l}\text { Any insurance } \\
\text { coverage }\end{array}$ & $0.792(0.406)$ & $0.748(0.434)$ & $0.849(0.358)$ & $0.727(0.446)$ & $0.829(0.376)$ \\
$\begin{array}{l}\text { Any private } \\
\text { Employer-sponsored }\end{array}$ & $0.668(0.471)$ & $0.618(0.486)$ & $0.721(0.449)$ & $0.609(0.488)$ & $0.717(0.450)$ \\
Individually purchased & $0.094(0.292)$ & $0.095(0.293)$ & $0.094(0.292)$ & $0.089(0.285)$ & $0.100(0.299)$ \\
Medicaid & $0.106(0.307)$ & $0.114(0.318)$ & $0.121(0.325)$ & $0.089(0.285)$ & $0.080(0.271)$ \\
Other & $0.032(0.176)$ & $0.030(0.172)$ & $0.024(0.152)$ & $0.041(0.198)$ & $0.043(0.203)$
\end{tabular}

Notes: Standard deviations are in parentheses.

Table 2. Implied Effects of the ACA at Mean Pre-Treatment Uninsured Rate for Full Sample

\begin{tabular}{|c|c|c|c|c|c|c|}
\hline & $\begin{array}{c}\text { Any } \\
\text { insurance }\end{array}$ & $\begin{array}{c}\text { Any } \\
\text { private }\end{array}$ & $\begin{array}{l}\text { Employer- } \\
\text { sponsored }\end{array}$ & $\begin{array}{l}\text { Individually } \\
\text { purchased }\end{array}$ & Medicaid & Other \\
\hline \multicolumn{7}{|c|}{ Non-elderly adults aged 19-64 (pre-treatment uninsured rate $=0.203$, sample size $=12,313,971$ ) } \\
\hline Medicaid & $0.051 * * *$ & -0.007 & 0.010 & -0.017 & $0.059 * * *$ & 0.001 \\
\hline Expansion & $(0.012)$ & $(0.011)$ & $(0.007)$ & $(0.014)$ & $(0.008)$ & $(0.001)$ \\
\hline $\begin{array}{l}\text { Full ACA (w/ } \\
\text { Medicaid) }\end{array}$ & $\begin{array}{c}0.087 * * * \\
(0.006)\end{array}$ & $\begin{array}{c}0.028 * * * \\
(0.006)\end{array}$ & $\begin{array}{c}0.018 * * * \\
(0.005)\end{array}$ & $\begin{array}{c}0.010 * * \\
(0.003)\end{array}$ & $\begin{array}{c}0.062 * * * \\
(0.007)\end{array}$ & $\begin{array}{c}0.000 \\
(0.001)\end{array}$ \\
\hline
\end{tabular}

Notes: Results are effects of the ACA on the proportion of residents with the specified type of insurance, evaluated at the mean pre-treatment uninsured rate. Standard errors, heteroscedasticity-robust and clustered by state, are in parentheses. ${ }^{* * *}$ indicates statistically significant at $0.1 \%$ level; ** $1 \%$ level; * $5 \%$ level. Sampling weights are used. All regressions include area and time fixed effects and the full set of controls. 
Table 3. Event Study Results for Full Sample - Pre-Reform Coefficients

\begin{tabular}{|c|c|c|c|c|c|c|}
\hline & $\begin{array}{c}\text { Any } \\
\text { insurance }\end{array}$ & $\begin{array}{c}\text { Any } \\
\text { private }\end{array}$ & $\begin{array}{l}\text { Employer- } \\
\text { sponsored }\end{array}$ & $\begin{array}{c}\text { Individually } \\
\text { purchased }\end{array}$ & Medicaid & Other \\
\hline \multicolumn{7}{|c|}{ PANEL I: FULL SAMPLE } \\
\hline \multicolumn{7}{|c|}{ Non-elderly adults aged 19-64 (pre-treatment uninsured rate $=0.203$, sample size $=12,313,971$ ) } \\
\hline Unin. Rate* & 0.030 & -0.0187 & -0.018 & -0.025 & 0.039 & 0.005 \\
\hline Med. Exp.*2011 & $(0.030)$ & $(0.036)$ & $(0.037)$ & $(0.020)$ & $(0.027)$ & $(0.010)$ \\
\hline Unin. Rate* & -0.021 & -0.009 & -0.012 & -0.008 & -0.007 & -0.007 \\
\hline Med. Exp.*2012 & $(0.039)$ & $(0.034)$ & $(0.028)$ & $(0.026)$ & $(0.015)$ & $(0.005)$ \\
\hline Uninsured & 0.010 & 0.031 & 0.008 & $0.040 * *$ & -0.008 & -0.005 \\
\hline Rate*2011 & $(0.023)$ & $(0.032)$ & $(0.032)$ & $(0.014)$ & $(0.016)$ & $(0.008)$ \\
\hline Uninsured & 0.043 & 0.037 & 0.008 & $0.046 * * *$ & 0.010 & 0.001 \\
\hline Rate*2012 & $(0.033)$ & $(0.030)$ & $(0.024)$ & $(0.013)$ & $(0.009)$ & $(0.003)$ \\
\hline
\end{tabular}

Notes: Coefficient estimates are shown. Standard errors, heteroscedasticity-robust and clustered by state, are in parentheses. *** indicates statistically significant at $0.1 \%$ level; ** $1 \%$ level; * $5 \%$ level. Sampling weights are used. All regressions include area and time fixed effects, the full set of controls, Medicaid Expansion*2011, and Medicaid Expansion*2012. 
Table 4. Event Study Results for Full Sample - Post-Reform Implied Effects

\begin{tabular}{|c|c|c|c|c|c|c|}
\hline & $\begin{array}{c}\text { Any } \\
\text { insurance }\end{array}$ & $\begin{array}{c}\text { Any } \\
\text { private }\end{array}$ & $\begin{array}{l}\text { Employer- } \\
\text { sponsored }\end{array}$ & $\begin{array}{c}\text { Individually } \\
\text { purchased }\end{array}$ & Medicaid & Other \\
\hline \multicolumn{7}{|c|}{ Non-elderly adults aged 19-64 (pre-treatment uninsured rate $=0.203$ ) } \\
\hline \multicolumn{7}{|c|}{ PANEL I: ACA without Medicaid Expansion } \\
\hline ACA w/o Medicaid & $0.029 * * *$ & $0.028 * * *$ & $0.011^{* * *}$ & 0.019 & 0.002 & -0.001 \\
\hline Expansion $2014(\mathrm{~A})$ & $(0.009)$ & $(0.008)$ & $(0.002)$ & $(0.010)$ & $(0.003)$ & $(0.001)$ \\
\hline ACA w/o Medicaid & $0.046 * *$ & $0.045 * *$ & 0.010 & $0.036^{*}$ & 0.004 & -0.0002 \\
\hline Expansion 2015 (A) & $(0.016)$ & $(0.013)$ & $(0.004)$ & $(0.017)$ & $(0.005)$ & $(0.001)$ \\
\hline ACA w/o Medicaid & $0.048 * *$ & $0.047 * *$ & $0.010 * * *$ & $0.038 *$ & 0.004 & -0.001 \\
\hline Expansion 2016 (A) & $(0.018)$ & $(0.014)$ & $(0.003)$ & $(0.016)$ & $(0.006)$ & $(0.002)$ \\
\hline ACA w/o Medicaid & $0.036^{*}$ & $0.035^{*}$ & 0.003 & $0.036^{*}$ & 0.004 & -0.001 \\
\hline Expansion 2017 (A) & $(0.017)^{\gamma \gamma \gamma}$ & $(0.015)^{\gamma \gamma \gamma}$ & $(0.003) \pi^{\gamma \gamma}$ & $(0.017)++$ & $(0.004)$ & $(0.002)$ \\
\hline \multicolumn{7}{|c|}{ PANEL II: Medicaid Expansion } \\
\hline $\begin{array}{l}\text { Medicaid Expansion } 2014 \\
\text { (B) }\end{array}$ & $\begin{array}{c}0.032 * * \\
(0.010)\end{array}$ & $\begin{array}{l}-0.001 \\
(0.009)\end{array}$ & $\begin{array}{c}0.007 \\
(0.004)\end{array}$ & $\begin{array}{l}-0.008 \\
(0.010)\end{array}$ & $\begin{array}{c}0.033^{* * *} \\
(0.007)\end{array}$ & $\begin{array}{c}0.001 \\
(0.001)\end{array}$ \\
\hline $\begin{array}{l}\text { Medicaid Expansion } 2015 \\
\text { (B) }\end{array}$ & $\begin{array}{c}0.047 * * \\
(0.016)\end{array}$ & $\begin{array}{l}-0.013 \\
(0.015)\end{array}$ & $\begin{array}{c}0.005 \\
(0.006)\end{array}$ & $\begin{array}{l}-0.020 \\
(0.017)\end{array}$ & $\begin{array}{c}0.062 * * * \\
(0.009)\end{array}$ & $\begin{array}{l}-0.0001 \\
(0.002)\end{array}$ \\
\hline $\begin{array}{l}\text { Medicaid Expansion } 2016 \\
\text { (B) }\end{array}$ & $\begin{array}{c}0.059 * * \\
(0.018)\end{array}$ & $\begin{array}{l}-0.015 \\
(0.016)\end{array}$ & $\begin{array}{c}0.009 \\
(0.006)\end{array}$ & $\begin{array}{l}-0.025 \\
(0.016)\end{array}$ & $\begin{array}{c}0.075^{* * *} \\
(0.010)\end{array}$ & $\begin{array}{c}0.001 \\
(0.002)\end{array}$ \\
\hline $\begin{array}{l}\text { Medicaid Expansion } 2017 \\
\text { (B) }\end{array}$ & $\begin{array}{c}0.070^{* * *} \\
(0.018) \mathrm{H+1} \\
\end{array}$ & $\begin{array}{l}-0.009 \\
(0.016)\end{array}$ & $\begin{array}{c}0.011 \\
(0.009)\end{array}$ & $\begin{array}{l}-0.024 \\
(0.017)\end{array}$ & $\begin{array}{l}0.080^{* * *} \\
(0.009)+++\end{array}$ & $\begin{array}{c}0.002 \\
(0.002)\end{array}$ \\
\hline \multicolumn{7}{|l|}{ PANEL III: Full ACA } \\
\hline Full ACA $2014(\mathrm{~A}+\mathrm{B})$ & $\begin{array}{c}0.061^{* * *} \\
(0.004)\end{array}$ & $\begin{array}{l}0.028^{* * *} \\
(.005)\end{array}$ & $\begin{array}{c}.018^{* * * *} \\
(.004)\end{array}$ & $\begin{array}{c}0.010 * * * \\
(0.003)\end{array}$ & $\begin{array}{c}0.035^{* * *} \\
(0.006)\end{array}$ & $\begin{array}{l}-0.0000 \\
(0.001)\end{array}$ \\
\hline Full ACA 2015 (A+B) & $\begin{array}{c}0.093 * * * \\
(0.006)\end{array}$ & $\begin{array}{c}.032 * * * \\
(.006)\end{array}$ & $\begin{array}{l}.015^{* *} \\
(.004)\end{array}$ & $\begin{array}{c}0.016^{* * *} \\
(0.003)\end{array}$ & $\begin{array}{c}0.066^{* * *} \\
(0.008)\end{array}$ & $\begin{array}{l}-0.0003 \\
(0.001)\end{array}$ \\
\hline Full ACA $2016(\mathrm{~A}+\mathrm{B})$ & $\begin{array}{c}0.107 * * * \\
(0.005)\end{array}$ & $\begin{array}{l}.032 * * * \\
(.007)\end{array}$ & $\begin{array}{l}.019 * * \\
(.006)\end{array}$ & $\begin{array}{c}0.012^{* * *} \\
(0.003)\end{array}$ & $\begin{array}{c}0.079 * * * \\
(0.008)\end{array}$ & $\begin{array}{l}0.0001 \\
(0.002)\end{array}$ \\
\hline Full ACA 2017 (A+B) & $\begin{array}{l}0.106 * * * \\
(0.006)+++\end{array}$ & $\begin{array}{c}.026 * * * \\
(.007)\end{array}$ & $\begin{array}{l}.014 \\
(.008)\end{array}$ & $\begin{array}{c}0.012^{* *} \\
(0.004)\end{array}$ & $\begin{array}{l}0.084 * * * \\
(0.007)+++\end{array}$ & $\begin{array}{c}0.001 \\
(0.001)\end{array}$ \\
\hline
\end{tabular}

Notes: Coefficient estimates are shown. Standard errors, heteroscedasticity-robust and clustered by state, are in parentheses. $* * *$ indicates statistically significant at $0.1 \%$ level; ** $1 \%$ level; * $5 \%$ level. Statistically significantly different effect in 2017 relative to 2014 is denoted by $\dagger \dagger \dagger$ at $0.1 \%$ level, $\dagger \dagger$ at $1 \%$ level and $\dagger$ at $5 \%$ level.

Statistically significantly different effect in 2017 relative to 2016 is denoted by $\gamma \gamma \gamma$ at $0.1 \%$ level, $\gamma \gamma$ at $1 \%$ level and $\gamma$ at $5 \%$ level. Sampling weights are used. All regressions include area and time fixed effects, the full set of controls. 
Table 5. Implied Effects of the ACA at Mean Pre-Treatment Uninsured Rate for Income and Race Subsamples

\begin{tabular}{|c|c|c|c|c|c|c|}
\hline & $\begin{array}{c}\text { Any } \\
\text { insurance }\end{array}$ & $\begin{array}{c}\text { Any } \\
\text { private }\end{array}$ & $\begin{array}{l}\text { Employer- } \\
\text { sponsored }\end{array}$ & $\begin{array}{c}\text { Individually } \\
\text { purchased }\end{array}$ & Medicaid & Other \\
\hline \multicolumn{7}{|c|}{ PANEL I: INCOME SUBSAMPLES } \\
\hline \multicolumn{7}{|c|}{ Under 138\% FPL (Pre-Treatment Uninsured Rate $=0.395$, sample size $=2,237,808)$} \\
\hline Medicaid & $0.184 * * *$ & -0.015 & 0.004 & -0.021 & $0.211^{* * *}$ & -0.002 \\
\hline Expansion & $(0.031)$ & $(0.016)$ & $(0.017)$ & $(0.023)$ & $(0.037)$ & $(0.002)$ \\
\hline & $0.170^{* * *}$ & 0.018 & & & & 0.001 \\
\hline Medicaid) & $(0.027)$ & $(0.011)$ & $(0.008)$ & $(0.007)$ & $(0.032)$ & $(0.002)$ \\
\hline \multicolumn{7}{|c|}{ 138\%-400\% FPL (Pre-Treatment Uninsured Rate $=0.238$, sample size $=4,814,696)$} \\
\hline Medicaid & $0.056 * * *$ & 0.007 & 0.030 & -0.020 & $0.051 * * *$ & 0.002 \\
\hline Expansion & $(0.016)$ & $(0.017)$ & $(0.015)$ & $(0.020)$ & $(0.013)$ & $(0.002)$ \\
\hline Full ACA (w/ & $0.106^{* * *}$ & $0.062 * * *$ & $0.050 * * *$ & $0.014 *$ & $0.047 * * *$ & 0.000 \\
\hline Medicaid) & $(0.012)$ & $(0.013)$ & $(0.011)$ & $(0.006)$ & $(0.012)$ & $(0.002)$ \\
\hline \multicolumn{7}{|c|}{ Over 400\% FPL (Pre-Treatment Uninsured Rate $=0.067$, sample size $=5,292,346)$} \\
\hline Medicaid & $0.010^{*}$ & 0.002 & 0.010 & -0.012 & 0.007 & -0.001 \\
\hline Expansion & $(0.004)$ & $(0.005)$ & $(0.009)$ & $(0.007)$ & $(0.003)$ & $(0.002)$ \\
\hline $\begin{array}{l}\text { Full ACA (w/ } \\
\text { Medicaid) }\end{array}$ & $\begin{array}{c}0.026 * * * \\
(0.003)\end{array}$ & $0.018 * * *$ & $\begin{array}{l}0.009 \\
(0.005)\end{array}$ & $\begin{array}{l}0.007 * \\
(0.003)\end{array}$ & $\begin{array}{l}0.007 * \\
(0.003)\end{array}$ & $\begin{array}{c}0.001 \\
(0.002)\end{array}$ \\
\hline & & & & & & \\
\hline
\end{tabular}

PANEL II: RACE / ETHNICITY SUBSAMPLES

Non-Hispanic White (Pre-Treatment Uninsured Rate $=0.145$, sample size $=8,336,484$ )

$\begin{array}{lcccccc}\text { Medicaid } & 0.048^{* * *} & 0.005 & 0.012 & -0.007 & 0.047 * * * & -0.002 \\ \text { Expansion } & (0.006) & (0.006) & (0.008) & (0.008) & (0.008) & (0.001) \\ \text { Full ACA (w/ } & 0.073^{* * *} & 0.021^{* * *} & 0.012^{* *} & 0.007^{*} & 0.061^{* * *} & -0.003^{* * *} \\ \text { Medicaid) } & (0.006) & (0.004) & (0.004) & (0.003) & (0.008) & (0.001)\end{array}$

Non-White (Pre-Treatment Uninsured Rate $=0.306$, sample size $=3,977,487$ )

\begin{tabular}{lcccccc} 
Medicaid & $0.072 * * *$ & -0.011 & 0.013 & -0.021 & $0.081^{* * *}$ & $0.007 * *$ \\
Expansion & $(0.021)$ & $(0.021)$ & $(0.011)$ & $(0.023)$ & $(0.013)$ & $(0.002)$ \\
Full ACA (w/ & $0.116^{* * *}$ & $0.036^{* * *}$ & $0.025^{* *}$ & $0.014^{*}$ & $0.078^{* * *}$ & $0.005^{* *}$ \\
Medicaid) & $(0.011)$ & $(0.009)$ & $(0.009)$ & $(0.005)$ & $(0.013)$ & $(0.002)$ \\
\hline
\end{tabular}

Notes: Results are effects of the ACA on the proportion of residents with the specified type of insurance, evaluated at the mean pre-treatment uninsured rate. Standard errors, heteroscedasticity-robust and clustered by state, are in parentheses. *** indicates statistically significant at $0.1 \%$ level; ** $1 \%$ level; * $5 \%$ level. Sampling weights are used. All regressions include area and time fixed effects and the full set of controls. 
Table 6. Implied Effects of the ACA at Mean Pre-Treatment Uninsured Rate for Marital Status and Age Subsamples

\begin{tabular}{|c|c|c|c|c|c|c|}
\hline & $\begin{array}{c}\text { Any } \\
\text { insurance }\end{array}$ & $\begin{array}{c}\text { Any } \\
\text { private }\end{array}$ & $\begin{array}{l}\text { Employer- } \\
\text { sponsored } \\
\end{array}$ & $\begin{array}{c}\text { Individually } \\
\text { purchased }\end{array}$ & Medicaid & Other \\
\hline \multicolumn{7}{|c|}{ PANEL I: MARITAL STATUS SUBSAMPLES } \\
\hline \multicolumn{7}{|c|}{ Married (Pre-Treatment Uninsured Rate $=0.141$, sample size $=6,977,652$ ) } \\
\hline Medicaid & $0.031 * * *$ & -0.004 & 0.0003 & -0.008 & $0.037 * * *$ & 0.001 \\
\hline Expansion & $(0.008)$ & $(0.007)$ & $(0.004)$ & $(0.008)$ & & $(0.001)$ \\
\hline & & & & & & \\
\hline & $(0.004)$ & (0.003) & & & & \\
\hline \multicolumn{7}{|c|}{ Unmarried (Pre-Treatment Uninsured Rate $=0.272$, sample size $=5,336,319)$} \\
\hline Medicaid & $0.084 * * *$ & -0.004 & 0.019 & -0.021 & $0.090 * * *$ & 0.002 \\
\hline Expansion & $(0.017)$ & $(0.015)$ & $(0.011)$ & $(0.015)$ & & $(0.002)$ \\
\hline $\begin{array}{l}\text { Full ACA (w/ } \\
\text { Medicaid) }\end{array}$ & $\begin{array}{c}0.119 * * * \\
(0.009)\end{array}$ & $\begin{array}{c}0.034 * * * \\
(0.009)\end{array}$ & $\begin{array}{c}0.027 * * * \\
(0.006)\end{array}$ & $\begin{array}{c}0.008 \\
(0.004)\end{array}$ & $\begin{array}{c}0.088 * * * \\
(0.011)\end{array}$ & $\begin{array}{c}0.002 \\
(0.001)\end{array}$ \\
\hline
\end{tabular}

PANEL II: AGE SUBSAMPLES

Ages 19-26 (pre-treatment uninsured rate $=0.270$, sample size $=1,821,602$ )

$\begin{array}{lcccccc}\text { Medicaid } & 0.077 * * * & -0.007 & 0.014 & -0.017 & 0.090^{* * *} & 0.002 \\ \text { Expansion } & (0.016) & (0.015) & (0.011) & (0.013) & (0.013) & (0.002) \\ \text { Full ACA (w/ } & 0.123^{* * *} & 0.029 * * & 0.025 * * & 0.006 & 0.097 * * * & 0.003^{*} \\ \text { Medicaid) } & (0.010) & (0.009) & (0.008) & (0.004) & (0.013) & (0.002)\end{array}$

Ages 27-34 (pre-treatment uninsured rate $=0.250$, sample size $=1,961,736$ )

$\begin{array}{lcccccc}\text { Medicaid } & 0.057 * * * & -0.007 & 0.001 & -0.007 & 0.070 * * * & 0.002 \\ \text { Expansion } & (0.012) & (0.011) & (0.009) & (0.009) & (0.011) & (0.003) \\ \text { Full ACA (w/ } & 0.094^{* * *} & 0.020^{*} & 0.009 & 0.009 * & 0.078^{* * *} & 0.003 \\ \text { Medicaid) } & (0.009) & (0.008) & (0.007) & (0.003) & (0.009) & (0.003)\end{array}$

Ages 35-49 (pre-treatment uninsured rate $=0.201$, sample size $=3,885,153$ )

$\begin{array}{lcccccc}\text { Medicaid } & 0.036^{* *} & -0.007 & 0.006 & -0.013 & 0.043^{* * *} & 0.001 \\ \text { Expansion } & (0.012) & (0.011) & (0.006) & (0.012) & (0.007) & (0.002) \\ \text { Full ACA (w/ } & 0.074 * * * & 0.028^{* * *} & 0.019 * * * & 0.009 * * & 0.047 * * * & 0.001 \\ \text { Medicaid) } & (0.005) & (0.005) & (0.005) & (0.003) & (0.006) & (0.001)\end{array}$

Ages 50-64 (pre-treatment uninsured rate $=0.145$, sample size $=4,645,480$ )

$\begin{array}{lcccccc}\text { Medicaid } & 0.031^{* * *} & -0.009 & 0.010 & -0.019 & 0.043^{* * *} & -0.001 \\ \text { Expansion } & (0.008) & (0.005) & (0.009) & (0.012) & (0.005) & (0.002) \\ \text { Full ACA (w/ } & 0.068^{* * *} & 0.029^{* * *} & 0.015^{* * *} & 0.013^{* * *} & 0.043^{* * *} & -0.002 \\ \text { Medicaid) } & (0.005) & (0.004) & (0.003) & (0.003) & (0.004) & (0.001)\end{array}$

Notes: Results are effects of the ACA on the proportion of residents with the specified type of insurance, evaluated at the mean pre-treatment uninsured rate. Standard errors, heteroscedasticity-robust and clustered by state, are in parentheses. ${ }^{* * *}$ indicates statistically significant at $0.1 \%$ level; ** $1 \%$ level; * $5 \%$ level. Sampling weights are used. All regressions include area and time fixed effects and the full set of controls. 
Table 7. Implied Effects of the ACA at Mean Pre-Treatment Uninsured Rate for Gender and Rural/Urban Subsamples

\begin{tabular}{|c|c|c|c|c|c|c|}
\hline & $\begin{array}{c}\text { Any } \\
\text { insurance }\end{array}$ & $\begin{array}{c}\text { Any } \\
\text { private }\end{array}$ & $\begin{array}{l}\text { Employer- } \\
\text { sponsored }\end{array}$ & $\begin{array}{c}\text { Individually } \\
\text { purchased }\end{array}$ & Medicaid & Other \\
\hline \multicolumn{7}{|c|}{ PANEL I: GENDER SUBSAMPLES } \\
\hline \multicolumn{7}{|c|}{ Women (Pre-Treatment Uninsured Rate $=0.186$, sample size $=6,389,974)$} \\
\hline $\begin{array}{l}\text { Medicaid } \\
\text { Expansion }\end{array}$ & $\begin{array}{c}0.063 * * * \\
(0.011)\end{array}$ & $\begin{array}{l}-0.002 \\
(0.009)\end{array}$ & $\begin{array}{c}0.012 \\
(0.011)\end{array}$ & $\begin{array}{l}-0.014 \\
(0.013)\end{array}$ & $\begin{array}{c}0.067 * * * \\
(0.013)\end{array}$ & $\begin{array}{c}0.002 \\
(0.002)\end{array}$ \\
\hline $\begin{array}{l}\text { Full ACA (w/ } \\
\text { Medicaid) }\end{array}$ & $\begin{array}{c}0.093 * * * \\
(0.007)\end{array}$ & $\begin{array}{c}0.030 * * * \\
(0.007)\end{array}$ & $\begin{array}{c}0.022 * * * \\
(0.005)\end{array}$ & $\begin{array}{c}0.007 \\
(0.004)\end{array}$ & $\begin{array}{c}0.065 * * * \\
(0.010)\end{array}$ & $\begin{array}{c}0.002 \\
(0.001)\end{array}$ \\
\hline \multicolumn{7}{|c|}{ Men (Pre-Treatment Uninsured Rate $=0.223$, sample size $=5,954,876)$} \\
\hline $\begin{array}{l}\text { Medicaid } \\
\text { Expansion }\end{array}$ & $\begin{array}{c}0.054^{* * *} \\
(0.013)\end{array}$ & $\begin{array}{l}-0.004 \\
(0.012)\end{array}$ & $\begin{array}{c}0.019 \\
(0.011)\end{array}$ & $\begin{array}{l}-0.020 \\
(0.018)\end{array}$ & $\begin{array}{c}0.061^{* * *} \\
(0.010)\end{array}$ & $\begin{array}{l}-0.001 \\
(0.002)\end{array}$ \\
\hline $\begin{array}{l}\text { Full ACA (w/ } \\
\text { Medicaid) }\end{array}$ & $\begin{array}{c}0.095 * * * \\
(0.008)\end{array}$ & $\begin{array}{c}0.038 * * * \\
(0.008)\end{array}$ & $\begin{array}{c}0.029 * * * \\
(0.006)\end{array}$ & $\begin{array}{l}0.012 * \\
(0.005)\end{array}$ & $\begin{array}{c}0.061^{* * *} \\
(0.010)\end{array}$ & $\begin{array}{l}-0.000 \\
(0.002)\end{array}$ \\
\hline
\end{tabular}

PANEL II: RURAL vs. URBAN SUBSAMPLES

Rural (pre-treatment uninsured rate $=0.211$, sample size $=2,282,428$ )

$\begin{array}{lcccccc}\text { Medicaid } & 0.081^{* * *} & -0.004 & -0.007 & 0.005 & 0.087 * * * & -0.001 \\ \text { Expansion } & (0.016) & (0.013) & (0.011) & (0.011) & (0.022) & (0.004) \\ \text { Full ACA (w/ } & 0.111^{* * *} & 0.026 * & 0.015 & 0.004 & 0.094 * * * & -0.004 \\ \text { Medicaid) } & (0.015) & (0.011) & (0.008) & (0.009) & (0.021) & (0.002)\end{array}$

Urban (pre-treatment uninsured rate $=0.203$, sample size $=10,062,422$ )

\begin{tabular}{lcccccc} 
Medicaid & $0.054^{* * *}$ & -0.002 & 0.019 & -0.019 & $0.059 * * *$ & -0.001 \\
Expansion & $(0.012)$ & $(0.011)$ & $(0.011)$ & $(0.016)$ & $(0.009)$ & $(0.002)$ \\
Full ACA (w/ & $0.090^{* * *}$ & $0.034^{* * *}$ & $0.027 * * *$ & $0.009^{*}$ & $0.058^{* * *}$ & 0.001 \\
Medicaid) & $(0.008)$ & $(0.007)$ & $(0.006)$ & $(0.004)$ & $(0.009)$ & $(0.001)$ \\
\hline
\end{tabular}

Notes: Results are effects of the ACA on the proportion of residents with the specified type of insurance, evaluated at the mean pre-treatment uninsured rate. Standard errors, heteroscedasticity-robust and clustered by state, are in parentheses. $* * *$ indicates statistically significant at $0.1 \%$ level; ** $1 \%$ level; * $5 \%$ level. Sampling weights are used. All regressions include area and time fixed effects and the full set of controls. 
Figure 1. Changes in Insurance Coverage Over Time

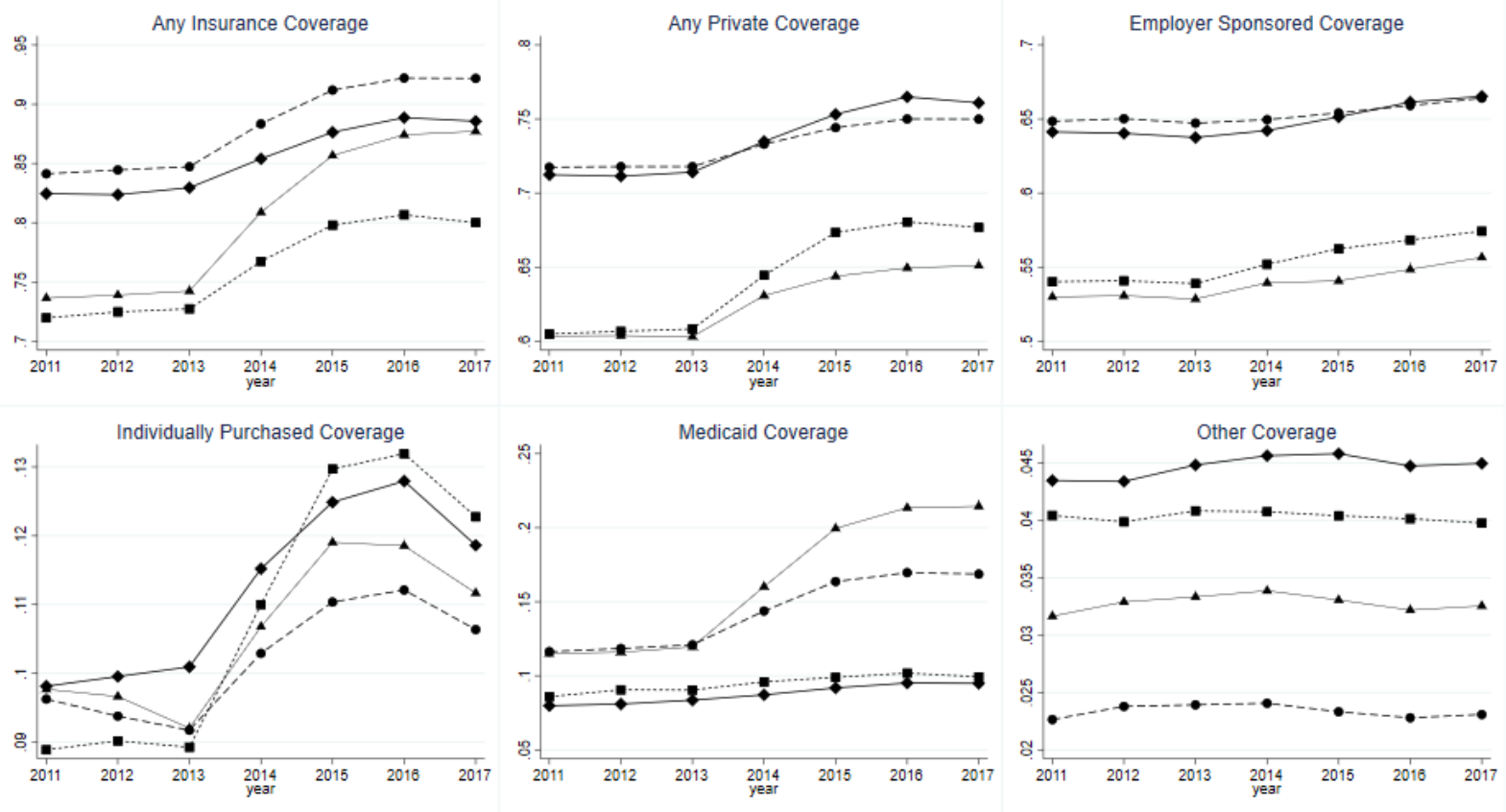

$$
\begin{aligned}
& \text { Above Median Local Area Uninsured Rate and Expanded Medicaid } \\
& - \text { Below Median Local Area Uninsured Rate and No Expansion }
\end{aligned}
$$




\section{APPENDIX:}

Table A1. Pre-Treatment Summary Statistics for Control Variables

\begin{tabular}{|c|c|c|c|c|c|}
\hline & $\begin{array}{c}\text { Full } \\
\text { Sample }\end{array}$ & $\begin{array}{c}\text { Medicaid } \\
\text { Expansion; } \\
\text { at or above } \\
\text { Median } \\
\text { Baseline } \\
\text { Uninsured }\end{array}$ & $\begin{array}{c}\text { Medicaid } \\
\text { Expansion; } \\
\text { below } \\
\text { Median } \\
\text { Baseline } \\
\text { Uninsured }\end{array}$ & $\begin{array}{c}\text { Non- } \\
\text { Expansion; } \\
\text { at or above } \\
\text { Median } \\
\text { Baseline } \\
\text { Uninsured }\end{array}$ & $\begin{array}{c}\text { Non- } \\
\text { Expansion; } \\
\text { below } \\
\text { Median } \\
\text { Baseline } \\
\text { Uninsured } \\
\end{array}$ \\
\hline \multicolumn{6}{|l|}{ Demographic controls } \\
\hline \multicolumn{6}{|c|}{ Age dummies (19-24 is omitted base category) ${ }^{a}$} \\
\hline Age 25-29 & $\begin{array}{c}0.110 \\
(0.313)\end{array}$ & $\begin{array}{c}0.114 \\
(0.318)\end{array}$ & $\begin{array}{c}0.109 \\
(0.311)\end{array}$ & $\begin{array}{c}0.108 \\
(0.311)\end{array}$ & $\begin{array}{c}0.113 \\
(0.317)\end{array}$ \\
\hline Age 30-34 & $\begin{array}{c}0.109 \\
(0.311)\end{array}$ & $\begin{array}{c}0.111 \\
(0.314)\end{array}$ & $\begin{array}{c}0.106 \\
(0.308)\end{array}$ & $\begin{array}{c}0.108 \\
(0.311)\end{array}$ & $\begin{array}{c}0.112 \\
(0.315)\end{array}$ \\
\hline Age 35-39 & $\begin{array}{c}0.104 \\
(0.305)\end{array}$ & $\begin{array}{c}0.105 \\
(0.307)\end{array}$ & $\begin{array}{c}0.101 \\
(0.301)\end{array}$ & $\begin{array}{c}0.106 \\
(0.308)\end{array}$ & $\begin{array}{c}0.103 \\
(0.304)\end{array}$ \\
\hline Age 40-44 & $\begin{array}{c}0.111 \\
(0.314)\end{array}$ & $\begin{array}{c}0.110 \\
(0.313)\end{array}$ & $\begin{array}{c}0.111 \\
(0.314)\end{array}$ & $\begin{array}{c}0.113 \\
(0.317)\end{array}$ & $\begin{array}{c}0.109 \\
(0.312)\end{array}$ \\
\hline Age 45-49 & $\begin{array}{c}0.114 \\
(0.318)\end{array}$ & $\begin{array}{c}0.110 \\
(0.313)\end{array}$ & $\begin{array}{c}0.116 \\
(0.321)\end{array}$ & $\begin{array}{c}0.114 \\
(0.317)\end{array}$ & $\begin{array}{c}0.112 \\
(0.315)\end{array}$ \\
\hline Age 50-54 & $\begin{array}{c}0.118 \\
(0.323)\end{array}$ & $\begin{array}{c}0.114 \\
(0.318)\end{array}$ & $\begin{array}{c}0.122 \\
(0.328)\end{array}$ & $\begin{array}{c}0.116 \\
(0.321)\end{array}$ & $\begin{array}{c}0.118 \\
(0.322)\end{array}$ \\
\hline Age 55-59 & $\begin{array}{c}0.109 \\
(0.311)\end{array}$ & $\begin{array}{c}0.105 \\
(0.306)\end{array}$ & $\begin{array}{c}0.112 \\
(0.316)\end{array}$ & $\begin{array}{c}0.107 \\
(0.309)\end{array}$ & $\begin{array}{c}0.108 \\
(0.310)\end{array}$ \\
\hline Age 60-64 & $\begin{array}{c}0.095 \\
(0.294)\end{array}$ & $\begin{array}{c}0.093 \\
(0.290)\end{array}$ & $\begin{array}{c}0.098 \\
(0.297)\end{array}$ & $\begin{array}{c}0.096 \\
(0.294)\end{array}$ & $\begin{array}{c}0.092 \\
(0.289)\end{array}$ \\
\hline Female & $\begin{array}{c}0.510 \\
(0.500)\end{array}$ & $\begin{array}{c}0.506 \\
(0.500)\end{array}$ & $\begin{array}{c}0.509 \\
(0.500)\end{array}$ & $\begin{array}{c}0.513 \\
(0.500)\end{array}$ & $\begin{array}{c}0.510 \\
(0.500)\end{array}$ \\
\hline \multicolumn{6}{|c|}{ Race/ethnicity dummies (non-Hispanic white is omitted base category) } \\
\hline Non-Hispanic black & $\begin{array}{c}0.121 \\
(0.326)\end{array}$ & $\begin{array}{c}0.083 \\
(0.275)\end{array}$ & $\begin{array}{c}0.105 \\
(0.307)\end{array}$ & $\begin{array}{c}0.169 \\
(0.375)\end{array}$ & $\begin{array}{c}0.135 \\
(0.341)\end{array}$ \\
\hline Hispanic & $\begin{array}{c}0.163 \\
(0.369)\end{array}$ & $\begin{array}{c}0.272 \\
(0.445)\end{array}$ & $\begin{array}{c}0.107 \\
(0.310)\end{array}$ & $\begin{array}{c}0.198 \\
(0.399)\end{array}$ & $\begin{array}{c}0.071 \\
(0.256)\end{array}$ \\
\hline Other & $\begin{array}{c}0.080 \\
(0.271)\end{array}$ & $\begin{array}{c}0.101 \\
(0.301)\end{array}$ & $\begin{array}{c}0.095 \\
(0.293)\end{array}$ & $\begin{array}{c}0.051 \\
(0.221)\end{array}$ & $\begin{array}{c}0.053 \\
(0.227)\end{array}$ \\
\hline Foreign born & $\begin{array}{c}0.171 \\
(0.376)\end{array}$ & $\begin{array}{c}0.230 \\
(0.421)\end{array}$ & $\begin{array}{c}0.168 \\
(0.374)\end{array}$ & $\begin{array}{c}0.162 \\
(0.369)\end{array}$ & $\begin{array}{c}0.093 \\
(0.291)\end{array}$ \\
\hline US citizen & $\begin{array}{c}0.904 \\
(0.295)\end{array}$ & $\begin{array}{c}0.867 \\
(0.340)\end{array}$ & $\begin{array}{c}0.914 \\
(0.281)\end{array}$ & $\begin{array}{c}0.900 \\
(0.300)\end{array}$ & $\begin{array}{c}0.944 \\
(0.231)\end{array}$ \\
\hline Married & $\begin{array}{c}0.520 \\
(0.500)\end{array}$ & $\begin{array}{c}0.508 \\
(0.500)\end{array}$ & $\begin{array}{c}0.518 \\
(0.500)\end{array}$ & $\begin{array}{c}0.521 \\
(0.500)\end{array}$ & $\begin{array}{c}0.544 \\
(0.498)\end{array}$ \\
\hline \multicolumn{6}{|c|}{ Dummies for number of children in home (none is omitted base category) } \\
\hline One child & $\begin{array}{c}0.158 \\
(0.365)\end{array}$ & $\begin{array}{c}0.162 \\
(0.368)\end{array}$ & $\begin{array}{c}0.157 \\
(0.364)\end{array}$ & $\begin{array}{c}0.160 \\
(0.366)\end{array}$ & $\begin{array}{c}0.155 \\
(0.362)\end{array}$ \\
\hline Two children & 0.133 & 0.135 & 0.133 & 0.130 & 0.134 \\
\hline
\end{tabular}




$\begin{array}{lccccc} & (0.339) & (0.341) & (0.340) & (0.336) & (0.341) \\ \text { Three children } & 0.052 & 0.057 & 0.049 & 0.053 & 0.054 \\ \text { Four children } & (0.223) & (0.233) & (0.215) & (0.224) & (0.227) \\ \text { Five children or more } & 0.015 & 0.017 & 0.013 & 0.016 & 0.018 \\ & (0.123) & (0.131) & (0.115) & (0.124) & (0.132) \\ & 0.006 & 0.007 & 0.006 & 0.006 & 0.007 \\ & (0.077) & (0.083) & (0.075) & (0.075) & (0.082)\end{array}$

\section{Economic controls}

Education dummies (less than high school degree is omitted base category)

\begin{tabular}{|c|c|c|c|c|c|}
\hline High school degree & $\begin{array}{c}0.268 \\
(0.443)\end{array}$ & $\begin{array}{c}0.259 \\
(0.438)\end{array}$ & $\begin{array}{c}0.263 \\
(0.440)\end{array}$ & $\begin{array}{c}0.286 \\
(0.452)\end{array}$ & $\begin{array}{c}0.263 \\
(0.440)\end{array}$ \\
\hline Some College & $\begin{array}{c}0.329 \\
(0.470)\end{array}$ & $\begin{array}{c}0.337 \\
(0.473)\end{array}$ & $\begin{array}{c}0.318 \\
(0.466)\end{array}$ & $\begin{array}{c}0.333 \\
(0.471)\end{array}$ & $\begin{array}{c}0.343 \\
(0.475)\end{array}$ \\
\hline College graduate & $\begin{array}{c}0.286 \\
(0.452)\end{array}$ & $\begin{array}{c}0.253 \\
(0.435)\end{array}$ & $\begin{array}{c}0.328 \\
(0.469)\end{array}$ & $\begin{array}{c}0.243 \\
(0.429)\end{array}$ & $\begin{array}{c}0.306 \\
(0.461)\end{array}$ \\
\hline mployed & $\begin{array}{c}0.069 \\
(0.253)\end{array}$ & $\begin{array}{c}0.077 \\
(0.270)\end{array}$ & $\begin{array}{c}0.067 \\
(0.250)\end{array}$ & $\begin{array}{c}0.070 \\
(0.255)\end{array}$ & $\begin{array}{c}0.057 \\
(0.232)\end{array}$ \\
\hline e unemployment rate & $\begin{array}{c}8.161 \\
(1.593)\end{array}$ & $\begin{array}{c}9.222 \\
(1.550)\end{array}$ & $\begin{array}{c}8.040 \\
(1.426)\end{array}$ & $\begin{array}{c}7.970 \\
(1.423)\end{array}$ & $\begin{array}{c}7.082 \\
(1.479)\end{array}$ \\
\hline dent & $\begin{array}{c}0.110 \\
(0.313)\end{array}$ & $\begin{array}{c}0.113 \\
(0.316)\end{array}$ & $\begin{array}{c}0.109 \\
(0.311)\end{array}$ & $\begin{array}{c}0.106 \\
(0.308)\end{array}$ & $\begin{array}{c}0.118 \\
(0.322)\end{array}$ \\
\hline
\end{tabular}

Income dummies (Relative to the Federal Poverty Line) ${ }^{\mathrm{a}}$

$\begin{array}{lccccc}\text { Income }<100 \mathrm{FPL} & 0.144 & 0.160 & 0.126 & 0.163 & 0.131 \\ & (0.351) & (0.367) & (0.331) & (0.369) & (0.337) \\ 100 \mathrm{FPL} \leq & 0.171 & 0.193 & 0.143 & 0.199 & 0.158 \\ \text { Income }<200 \mathrm{FPL} & (0.376) & (0.395) & (0.350) & (0.400) & (0.364) \\ 200 \mathrm{FPL} \leq & 0.162 & 0.167 & 0.148 & 0.175 & 0.166 \\ \text { Income }<300 \mathrm{FPL} & (0.368) & (0.373) & (0.356) & (0.380) & (0.372) \\ \text { 300FPL } \leq & 0.136 & 0.131 & 0.136 & 0.135 & 0.146 \\ \text { Income }<400 \mathrm{FPL} & (0.343) & (0.337) & (0.343) & (0.342) & (0.353) \\ \text { 400FPL } \leq & 0.106 & 0.098 & 0.113 & 0.099 & 0.115 \\ \text { Income }<500 \mathrm{FPL} & (0.308) & (0.297) & (0.317) & (0.299) & (0.319) \\ \text { Income } \geq 500 \mathrm{FPL} & 0.282 & 0.251 & 0.333 & 0.229 & 0.285 \\ & (0.450) & (0.434) & (0.471) & (0.420) & (0.451) \\ & & & & & \\ \text { change controls } & 0.344 & 0.563 & 0.566 & \text { N/A } & \text { N/A } \\ \text { ate set up own exchange } & (0.475) & (0.496) & (0.496) & & \text { N/A } \\ & 0.084 & 0.065 & 0.178 & \text { N/A } & \end{array}$

Notes: Standard deviations are in parentheses.

${ }^{a}$ Our baseline model includes dummy variables for each year of age as well as dummy variables for each 10-point increment of the FPL (50 total dummies). To conserve space, we present our descriptive statistics for age and income in broader categories in this table. 